\title{
Chemotactic Factor for Polymorphonuclear Leukocytes Derived from Human Lung Giant Cell Carcinoma Lu65 Cells
}

\author{
Kazuo Suzuki, ${ }^{1, *}$ Hiromi Ota, ${ }^{1}$ Setsuo Hirohashi, ${ }^{2}$ Yoichi Taya, ${ }^{3}$ \\ Yukio Shimosato, ${ }^{2}$ Atsushi Kuramoto, ${ }^{4}$ and Toshio FujikurA ${ }^{1}$ \\ ${ }^{1}$ Department of Pathology, Radiation Effects Research \\ Foundation, Hiroshima 732, Japan \\ ${ }^{2}$ Divisions of Pathology and ${ }^{3}$ Biology, \\ National Cancer Center Research Institute, Tsukiji, Tokyo 104, Japan \\ ${ }^{4}$ Department of Internal Medicine, Research Institute for \\ Nuclear Medicine and Biology, Hiroshima University, \\ Kasumi-cho, Hiroshima 734, Japan
}

(Received October 28, 1988)

\begin{abstract}
Summary A chemotactic factor for polymorphonuclear leukocytes was found in the culture fluid of human lung giant cell carcinoma cell line Lu65. This factor was defined as chemotactic one by checkerboard analysis. Partial purification of the chemotactic factor was performed by DEAE-Sepharose and gel filtration with Sephadex G-100, which showed it to be basic and low molecular weight. The factor was also found in the filtrate of culture fluid passed through a Centriflo CF25 filter, thus indicating a molecular weight of less than $25 \mathrm{kDa}$. Furthermore, three cell clones having higher activity of chemoattractant were selected from the original cell line.
\end{abstract}

Key Words: chemotactic factor, lung carcinoma, polymorphonuclear leukocytes (PMN), cell cloning

Polymorphonuclear leukocytes (PMN) show cytotoxicity in vitro and damage tumor cells [1-7]. It has been reported that myeloperoxidase, hydrogen peroxide, superoxide anion, and lysosomal enzymes are involved in this tumor cell killing by PMN [4, 7-11]. PMN in vivo are required to migrate toward the inflamed site from the peripheral blood in order to manifest this function in sites of tumor cell

*To whom correspondence should be addressed. Present address: Department of Antibiotics, National Institute of Health, 2-10-35 Kami-osaki, Shinagawa-ku, Tokyo 141, Japan. Abbreviations: HBSS, Hanks' balanced salt solution; fMet-Leu-Phe, N-formyl-methionylleucyl-phenylalanine; PBS, phosphate-buffered saline without calcium and magnesium. 
growth. It has been observed that PMN infiltration into sites of inflammation occurs at the earliest stage, that is, PMN infiltrate into the site of tumor growth prior to infiltration of macrophages and lymphocytes $[12,13]$. This indicates that PMN migrate rapidly to the inflamed site. As PMN migrate toward chemoattractants produced at this site $[14,15]$, it is assumed that PMN infiltration must be stimulated with a chemoattractants produced by tumor cells in this region. For substantiation of this hypothesis, many PMN must be observed in the primary tissue of the tumor, and, furthermore, the presence of chemoattractants in cell lines established from the tumor must be confirmed.

An infiltrative picture of PMN has been observed in the cancer tissues of a lung giant cell carcinoma [16], and histological examination suggested that a PMN chemotactic factor might be secreted from this carcinoma. A cell line, Lu65 has been established from a specimen of this carcinoma, and colony stimulating factor is secreted by it [16]. Following tumor transplantation, remarkable leukocytosis without evidence of infection has been observed in nude mice [16]. Furthermore, amplification of onco-genes $K$-ras and myc was also observed in this cell line [17].

The present report describes the finding of chemotactic activity in the culture fluid of the Lu65 cell line and the conditions for its optimal production. Moreover, partial purification of the chemotactic factor was performed.

\section{MATERIALS AND METHODS}

Preparation of chemotactic factor from culture fluid. Lu65 cells were cultured in RPMI-1640 containing 10\% fetal bovine serum (GIBCO, NY). The chemotactic factor was obtained from the culture fluid of Lu65 cells by centrifugation for $10 \mathrm{~min}$ at $1,500 \times g$ at $4^{\circ} \mathrm{C}$, and the supernatant was used for the chemotactic assay.

Preparation of human PMN. Human PMN were obtained by the method described previously [18, 19]. Cells at a concentration of $2 \times 10^{6}$ cells $/ \mathrm{ml}$ were suspended in Hanks' balanced salt solution (HBSS) containing 0.3\% $\mathrm{NaHCO}_{3}$.

Migration assay. Migration activity of PMN was determined by the migration distance through a Millipore filter $(3 \mu \mathrm{m})$ in a modified Boyden chamber [20]. Culture medium conditioned by the Lu65 cells was placed in the lower well, and PMN suspension, in the upper well. After incubation of the chamber for 45 min at $37^{\circ} \mathrm{C}$ under an atmosphere of $5 \% \mathrm{CO}_{2}$ in air, the filter was fixed with ethanol and dried and stained with Weigert's hematoxylin. Migration distance from the upper chamber side of the filter to the leading edge of cells was measured with a high power microscope. The values were expressed as means of values determined in five microscopic fields. fMet-Leu-Phe $\left(10^{-8} \mathrm{M}\right)$ was used as a positive control.

Checkerboard analysis of culture fluid of Lu65 cells. In order to determine whether the supernatants contained chemotactic activity as well as the capacity for 
stimulation of locomotion, we placed different concentrations of supernatants in upper and lower compartments [21]. Migration distance for each concentration of the fluid was measured.

Filtration of culture fluid. The approximate molecular weight was determined by passage of culture medium through a Centriflo CF25 filter (Amicon Co., Denvers, MA). Lu65 cells were incubated for 6 days and the culture fluid was then taken and frozen at $-20^{\circ} \mathrm{C}$. After being thawed, $0.75 \mathrm{ml}$ of this culture fluid was filtered with a Centriflo CF25 by centrifugation for $15 \mathrm{~min}$ at $1,500 \times g$ at $4^{\circ} \mathrm{C}$. The non-filtered fraction was resuspended in HBSS.

Partial purification of the chemotactic factor from the culture fluid. Ten milliliters of the culture fluid was dialyzed against $50 \mathrm{~mm}$ sodium phosphate buffer $(\mathrm{pH} 7.4)$ overnight and applied to a DEAE-Sepharose column $(2.5 \times 10 \mathrm{~cm})$ equilibrated previously with $50 \mathrm{~mm}$ sodium phosphate buffer ( $\mathrm{pH} 7.4$ ). The chemotactic activity appeared in the pass-through fraction and the major part of the protein adsorbed to the column. The pass-through fraction containing chemotactic factor $(45 \mathrm{ml})$ was concentrated to $12 \mathrm{ml}$ in a dialysis tubing using polyethylene glycol (m.w. 2,000) and dialyzed against phosphate-buffered saline without calcium and magnesium (PBS). Five milliliters of the concentrated sample was applied to Sephadex G-100 column $(2.4 \times 90 \mathrm{~cm})$ equilibrated previously with PBS and eluted with the same.

Cloning of chemoattractant-producing cell from Lu65 cell line. Cells of the original line were plated at a density of $1 \times 10^{4}$ cells in $500 \mu 1$ into each well of a 24-well plate and cultured for 7 days. Cell populations possessing high chemotactic activity were transferred into new 24 -well plates at a 1/10 dilution with RPMI-1640 medium containing 10\% fetal bovine serum and cultured for 12 days. Furthermore, each of the populations having higher activity in the second selection was plated into 96-well plate as one cell per well and cultured from 14 to 23 days. After growth the cell colony in the well was picked up and used as a clonal cell line.

\section{RESULTS AND DISCUSSION}

\section{Optimal culture period to produce chemotactic factor}

As shown in Fig. 1, PMN migration was stimulated by the culture fluid of Lu65 cells but not by culture medium only which had been incubated under the same conditions as the cell culture. The highest stimulatory activity was observed in the fluid harvested at for 6 days. Whether this stimulation factor for PMN migration is a chemotactic factor was determined by checkerboard analysis. Table 1 shows checkerboard analysis of the chemotactic factor. PMN migrated to the culture fluid in the lower compartment in a dose-dependent manner and responded to that in the upper with inhibition. This indicates that culture fluid of Lu65 cells contained a chemotactic factor for PMN. 
Partial purification and approximate molecular weight of the chemotactic factor

When the culture fluid was applied to Centriflo CF25 filter and centrifuged, the chemotactic activity was detected in the filtrate (Table 2). These results suggest that the chemotactic factor secreted in the culture fluid by the Lu65 cells had a relatively low molecular weight one of less than $25 \mathrm{kDa}$. On the other hand, the

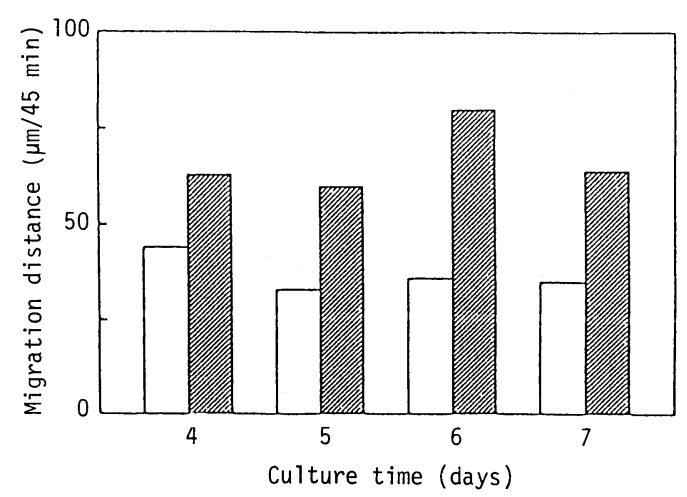

Fig. 1. Chemotactic activity in culture fluid of lung giant cell calcinoma LU65 cells. After preculture of Lu65 cells for 4 days, cells non-adherent and adherent to the plastic flask were removed by pipetting, and plated again in RPMI- 1640 containing $10 \%$ heat-treated fetal bovine serum. The cells were incubated for 4 to 7 days at $37^{\circ} \mathrm{C}$ in $5 \% \mathrm{CO}_{2}$. The culture fluid $(6-7 \mathrm{ml})$ was harvested after a lapse of time and centrifuged for $10 \mathrm{~min}$ at $1,500 \times g$ at $4^{\circ} \mathrm{C}$. The supernatant was used as an assay sample. $\mathrm{VIIIT}$, Lu65-conditioned culture fluid; $\square$, medium culture without cells.

Table 1. Checkerboard analysis of culture fluid from Lu65 cells.

\begin{tabular}{ccccc}
\hline & \multicolumn{4}{c}{ Migration distance $(\mu \mathrm{m} / 45 \mathrm{~min})$} \\
\cline { 2 - 4 } \% Fluid in lower & \multicolumn{4}{c}{ \% Fluid in upper compartment } \\
\cline { 2 - 4 } compartment & 27.1 & 25 & 50 & 100 \\
\hline 0 & 52.0 & 32.0 & 28.4 & 27.6 \\
25 & 60.1 & 34.9 & 39.5 & 29.4 \\
50 & 48.8 & 31.6 & 28.8 \\
100 & 82.5 & 57.6 & 42.5 & 31.1 \\
\hline
\end{tabular}

Table 2. Distribution of chemotactic factor in filtrate and non-filterable fraction of centriflo CF25 filtration.

\begin{tabular}{lcc}
\hline & \multicolumn{2}{c}{ Migration distance $(\mu \mathrm{m} / 45 \mathrm{~min})$} \\
\cline { 2 - 3 } Sample fraction & Conditioned culture fluid & Non-conditioned culture fluid \\
\hline Original fluid & 45.5 & 26.5 \\
Filtrate & 50.5 & 21.9 \\
Non-filterable fraction & 38.0 & 25.4 \\
Control fMet-Leu-Phe $\left(10^{-8} \mathrm{M}\right)$ & & 75.8 \\
\hline
\end{tabular}




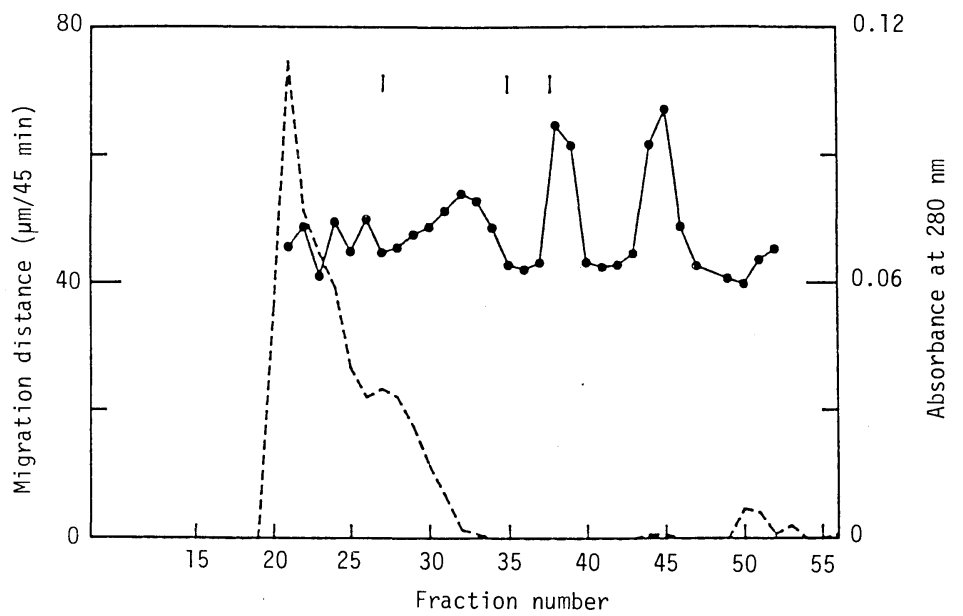

Fig. 2. Sephadex G-100 column chromatography. - - C Chemotactic activity; ----, absorbance at $280 \mathrm{~nm}$. Molecular markers used were bovine serum albumin, $66 \mathrm{kDa}$; chymotrypsin, $25 \mathrm{kDa}$; cytochrome $c, 12.5 \mathrm{kDa}$.

Table 3. Clones of chemoattractant-producing cells from the original cell line Lu65.

\begin{tabular}{lc}
\hline Cell clone & Migration distance $(\mu \mathrm{m} / 45 \mathrm{~min})$ \\
\hline Lu65-A & 51.6 \\
$\mathrm{~B}$ & 55.3 \\
C & 59.5 \\
Control & \\
Random migration & 37.9 \\
fMet-Leu-Phe $\left(10^{-8} \mathrm{M}\right)$ & 72.3 \\
\hline
\end{tabular}

factor was eluted in the pass-through fraction of DEAE-Sepharose column chromatography and it was eluted in fraction of less than $12.5 \mathrm{kDa}$ by Sephadex-G100 column chromatography (Fig. 2). These results strongly suggest that the factor may be a basic protein. Moreover, the molecular weight of this factor is relatively similar to that of complement C5a [22]. However, as the fetal bovine serum used in the present study was treated for $30 \mathrm{~min}$ at $56^{\circ} \mathrm{C}$, it is likely that C5a does not exist in the medium. In addition, medium cultured in the absence of cells did not show chemotactic activity (Fig. 1). These results strongly suggest that the chemotactic factor in culture of Lu65 is different from C5a.

\section{Cloning of chemoattractant-producing cell from Lu65 cell line}

Cells of the original line were plated into 24-well plates and cultured for 7 days. Of the 24 populations obtained, 5 possessed high chemotactic activity and were transferred to a new 24-well plate at a 1/10 dilution with RPMI-1640 medium containing $10 \%$ fetal bovine serum and cultured for 12 days. Furthermore, each of 
two populations having the highest activity in the second selection was plated into a 96-well plate at one cell per well and cultured from 14 to 23 days. The cell colony that appeared in a given well was picked up and cultured to establish a clonal cell line. Finally, three clones of chemoattractant-producing cells from the Lu65 cell line were selected (Table 3).

Bottazzi et al. [23] have demonstrated a chemotactic factor for macrophages in the supernatant of tumor cell cultures. The preliminary evidence for a PMN chemoattractant in the present study agrees with their observation. Their report and the present study suggest that macrophages and PMN participate in immunosurveillance of growth of tumor cells. Recently, it was reported that PMN are the first cells to infiltrate into the intraperitoneal site after injection of a stimulant such as casein or glycogen $[12,24]$. Furthermore, PMN have tumor-killing activity [1-7]. These findings suggest that PMN migrate via a tumor cell-secreted chemoattractant to sites of growing tumor cells to kill the tumor cells there. Hence, secretion of chemoattractant for PMN by tumor cells is important at the first step of immunosurveillance by PMN in their host-defense function.

\section{REFERENCES}

1. Pikaver, A.H., Ratcliffe, N.A., Williams, A.E., and Smith, H. (1972): Cytotoxic effects of peritoneal neutrophils on a syngeneic rat tumour. Nature New Biol., 235, 186-187.

2. Gale, R.P., and Zighelboim, J. (1975): Polymorphonuclear leukocytes in antibodydependent cellular cytotoxicity. J. Immunol., 114, 1047-1051.

3. Chee, D.D., Townsend, C.M., Gallbraith, M.A., Eiber, F.R., and Morton, D.L. (1978): Selective reduction of human tumor cell populations by human granulocytes in vitro. Cancer Res., 38, 4534-4539.

4. Nathan, C.F., Brukner, L.H., Silverstein, S.C., and Cohn, Z.A. (1979): Extracellular cytolysis by activated macrophages and granulocytes I. Pharmacologic trigering of effector cells and the release of hydrogen peroxide. J. Exp. Med., 149, 84-99.

5. Gerrard, T.L., Cohen, D.J., and Kaplan, A.M. (1981): Human neutrophil-mediated cytotoxicity to tumor cells. J. Natl. Cancer Inst., 66, 483-488.

6. Inoue, T., and Sendo, F. (1983): In vitro induction of cytotoxic polymorphonuclear leukocytes by supernatant from a concanavalin A-stimulated spleen cell culture. J. Immunol., 131, $2508-2514$.

7. Morikawa, K., Kamegaya, S., Yamazaki, M., and Mizuno, D. (1985): Hydrogen peroxide as a tumoricidal mediator of murine polymorphonuclear leukocytes induced by a linear $\beta-1,3-$ D-glucan and some other immunomodulators. Cancer Res., 45, 3482-3486.

8. Hafeman, D.G., and Locas, Z.J. (1979): Polymorphonuclear leukocyte-mediated, antibodydependent, cellular cytotoxicity against tumor cells: Dependence on oxygen and the respiratory burst. J. Immunol., 123, 55-62.

9. Weiss, S.J. (1980): The role of superoxide in the destruction of erythrocyte targets by human neutrophils. J. Biol. Chem., 255, 9912-9917.

10. Clark, R.A., and Klebanoff, S.J. (1975): Neutrophil-mediated tumor cell cytotoxicity: Role of the peroxidase system. J. Exp. Med., 141, 1442-1447.

11. Clark, R.A., and Klebanoff, S.J. (1979): Role of the myeloperoxidase- $\mathrm{H}_{2} \mathrm{O}_{2}$-halide system in concanavalin A-induced tumor cell killing by human neutrophils. J. Immunol., 122, 26052610.

12. Morikawa, K., Kikuchi, Y., Abe, S., Yamazaki, M., and Mizuno, D. (1984): Early cellular 
responses in the peritoneal cavity of mice to antitumor immunomodulators. Gann, 75, 370378 .

13. Goto, K., Nakamura, S., Goto, F., and Yoshinaga, M. (1984): Generation of an interleukinI-like lymphocyte-stimulating factor at inflammatory sites: Correlation with the infiltration of polymorphonuclear leukocytes. Br. J. Exp. Pathol., 65, 521-532.

14. Goldstein, I., Hoffstein, S., Gallin, J., and Weissmann, G. (1973): Mechanism of lysosomal enzyme release from human leukocytes: Microtuble assembly and membrane fusion induced by a component of complement. Proc. Natl. Acad. Sci. USA., 70, 2916-2920.

15. Marasco, W.A., Phan, S.H., Krutzsch, H., Showell, H.J., Feltner, D.E., Nairn, R., Becker, E. L., and Ward, P. (1984): Purification and identification of formyl-methionyl-leucyl-phenylalanine as the major peptide neutrophil chemotactic factor produced by Escherichia coli. $J$. Biol., Chem., 259, 5430-5439.

16. Yamada, T., Hirohashi, S., Shimosato, Y., Kodama, T., Hayashi, S., Ogura, T., Gamou, S., and Shimizu, N. (1985): Giant cell carcinomas of the lung producing colony-stimulating factor in vitro and in vivo. Jpn. J. Cancer Res. (Gann), 76, 967-976.

17. Taya, Y., Hosogai, K., Hirohashi, S., Shimosato, Y., Tsuchiya, R., Tsuchida, N., Fushimi, M., Sekiya, T., and Nishimura, S. (1984): A novel combination of $K$-ras and myc amplification accompanied by point mutational activation of $K$-ras in a human lung cancer. EMBO J., 3, 2942-2946.

18. Suzuki, K., Ota, H., Sasagawa, S., Sakatani, T., and Fujikura, T. (1983): Assay method for myeloperoxydase in human polymorphonuclear leukocyte. Anal. Biochem., 132, 345-352.

19. Suzuki, K., Asaoka, K., Takahashi, K., and Fujikura, T. (1985): Differences among primates in defence against infection: Sensitivity of polymorphonuclear leukocytes to fMet-Leu-Phe. Cell Biochem. Funct., 3, 297-303.

20. Suzuki, K., and Yamada, M. (1987): Differences in release from differentiated HL-60 cells between myeloperoxidase and $\beta$-glucuronidase. J. Clin. Biochem. Nutr., 4, 103-109.

21. Zigmond, S.H., and Hirsch, J.G. (1973): Leukocyte locomotion and chemotaxis. New methods for evaluation, and demonstration of a cell-derived chemotactic factor. J. Exp. Med., 137, 387-410.

22. Fernandez, H.N., and Hugli, T.E. (1976): Partial characterization of human C5a anaphylatoxin I. Chemical description of the carbohydrate and polypeptide portions of human C5a. J. Immunol., 117, 1688-1694.

23. Bottazzi, B., Polentarutti, N., and Aceto, R. (1982): Regulation of the macrophage content of neoplasms by chemoattractants. Science, 220, 210-212.

24. Yamashita, T., Ishibashi, Y., Nagaoka, I., Kasuya, K., Masuda, K., Warabi, H., and Shiokawa, Y. (1982): Studies on glycogen-induced inflammation of mice. Dynamics of inflammatory responses and influence of antiinflammatory drugs and protease inhibitors. Inflammation, 6, 87-101. 